\title{
Prevalence of Gastrointestinal Protozoa on Bali Cattle in Lopok Sub-District, Sumbawa District
}

\author{
${ }^{1)}$ Aldi Hamdani, ${ }^{2)}$ Nunuk Dyah Retno Lastuti (D) ${ }^{3)}$ Yeni Dhamayanti, ${ }^{2)}$ Setiawan Koesdarto, \\ ${ }^{2)}$ Agus Sunarso, ${ }^{2)}$ Poedji Hastutiek \\ ${ }^{1)}$ Student, Faculty of Veterinary Medicine, Airlangga University, aldi.hamdani-2017@fkh.unair.ac.id \\ ${ }^{2}$ Division of Veterinary Parasitology, Faculty of Veterinary Medicine, Airlangga University \\ ${ }^{3)}$ Division of Veterinary Anatomy, Faculty of Veterinary Medicine, Airlangga University
}

Received: 15-08-2021, Accepted: 25-08-2021, Published Online: 30-09-2021

Corresponding author: nunukdyah53@gmail.com

\begin{abstract}
This study aims to determine the prevalence of gastrointestinal protozoa on Bali cattle in Lopok Sub-District, Sumbawa District. The study was conducted from January to April 2021 by taking 100 samples of Bali cattle feces from 7 villages in Lopok Sub-District, Sumbawa District. Samples were examined by sedimentation and floating methods. Species identification was determined by the morphology of the protozoa. A total of $62(62 \%)$ samples were positively infected with protozoa. There were 4 species of gastrointestinal protozoa found infecting Bali cattle, namely Eimeria sp., Blastocytis sp., Entamoeba sp., and Balantidium sp. Most of the protozoa found in this study were Eimeria sp. (54\%) and Blastocytis sp. (5\%). This study found 59 samples (59\%) were infected by one type of protozoa, 3 samples $(3 \%)$ were infected by two types of protozoa. Cattle aged o- 6 months $(81 \%)$ had a higher prevalence rate and were more susceptible to protozoal infections than cows aged 7 months -2 years $(70.3 \%)$ and more than 2 years $(45.2 \%)$.
\end{abstract}

Keyword: Protozoa, Eimeria sp., Blastocytis sp., Entamoeba sp., Balantidium sp., Bali Cattle.

\section{Introduction}

Sumbawa District is one of four regencies and one city on the island of Sumbawa, West Nusa Tenggara Province. Sumbawa District makes the livestock sector as one of the leading sectors. One of the Sub-Districts in the Sumbawa District is Lopok Sub-District. The total population of cattle in the Lopok SubDistrict reaches 15,531 (BPS Sumbawa District, 2020).

The problem of parasitic disease is one of the problems that must be known by farmers to avoid large economic losses. Drum sanitation plays a very important role in the health and productivity of livestock (Widyani, 2013). The incidence of gastrointestinal parasitic disease infection attacks people's farms with semiintensive and extensive maintenance systems. The cattle are released and left to find their food in the pasture. Kantzoura et al. (2012) environmental factors affect the prevalence of gastrointestinal protozoa infections such as climate change, environmental temperature, humidity, altitude of an area, rainfall, and soil conditions. Transmission of the infective stage of the protozoa can occur in the cage when the cow is in the pen, causing a high risk of transmission among Bali cattle that are kept (Rahmawati et al. 2018).

Gastrointestinal protozoa that live in the digestive tract greatly affect the health of Bali cattle (Indraswari et al., 2017). Gastrointestinal protozoa infect the digestive tract causing livestock to experience a decrease in nutrient absorption resulting in growth delays so that the quality of Bali cattle decreases (Astiti et al., 2011).

Protozoa are single-celled organisms. In some species of protozoa have more than one nucleus (nucleus) in part or throughout the life cycle (Setywan, 2013). Several gastrointestinal protozoa that can be found in cattle are from the Genus Entamoeba sp., Balantidium sp., Criptospirodium sp., Giardia sp., Eimeria sp., and Blastocystis sp. (Nugroho, 2014).

The prevalence of gastrointestinal parasites has been studied with different prevalence results. Huang et al., (2014) in Taiwan showed a high prevalence of protozoa infection with a percentage of $81.3 \%$. Susana et al (2019) in Siak Sri Indrapura District on the prevalence of 
gastrointestinal parasites in beef cattle showed that out of 100 stool samples examined, $100 \%$ positive for parasite infection. Hastutiek et al. (2019) reported the prevalence rate of gastrointestinal protozoan infections in Madura cattle in Bangkalan District reached 71.4\% (357) of a total of 500 Madura cattle feces samples with the identification of protozoa consisting of Eimeria sp., Balantidium sp., Isospora sp., Blastocytis sp., Entamoeba sp., and Cryptosporidium sp., genus Balantidium sp., Entamoeba sp., Blastocystis sp., and Cryptosporidium sp. have zoonotic potential.

The livestock rearing system in Lopok SubDistrict, Sumbawa District uses an extensive and semi-intensive maintenance system. Cows are left to forage on their own and are rarely rotated to grazing fields. Placement of livestock in one cage regardless of age and gender. The cages are still traditional with a tin roof and grounded so that it can cause the risk of livestock being infected with parasites.

According to Apsari et al. (2016), the factors that influence the prevalence of gastrointestinal protozoal infections are animal age, sex, physiological conditions and animal immunity, contamination by parasites, maintenance management including treatment and maintenance systems, sanitation, population density, geographical distribution and the condition of an area.

This study was conducted to determine the prevalence of gastrointestinal protozoa, types of gastrointestinal protozoa, and the effect of age on the prevalence of gastrointestinal protozoa in Bali cattle in Lopok Sub-District, Sumbawa District. Data on the prevalence of gastrointestinal protozoa is expected to be used in the prevention and eradication of gastrointestinal diseases to prevent losses to farmers.

\section{Materials and Methods}

Fecal sampling was carried out in seven villages in Lopok Sub-District, Sumbawa District, namely Mama, Berora, Langam, Pungkit, Tatede, Lopok and Lopok Beru villages. Then potassium dichromate is added as a preservative. Feces was taken from cows that had just defecated. Each plastic pot is labeled with age, gender, and sampling location. Samples were examined using the sedimentation method and the floating method at the Veterinary Parasitology Laboratory,
Faculty of Veterinary Medicine, Airlangga University.

Sedimentation method, the suspension was made with a ratio of 1: 10 (feces : water), the suspension was stirred and filtered using a sieve that was accommodated in a plastic cup. The results of the filter or filtrate were put into a centrifuge tube and then centrifuged at 1500 rpm for approximately $2-5$ minutes. The supernatant was discarded and the precipitate was added with water and centrifuged again. This process was repeated until the supernatant was clear. After the supernatant was clear, then discard it and leave it a little then it can be stirred and taken using a Pasteur pipette, place on a glass slide covered with a coverslip then examine with a microscope with a magnification of 10ox (Mumpuni et al, 2017).

The working procedure of the floating method is similar to that of sedimentation. After being clear, the supernatant was discarded and then a saturated sugar solution was added up to $1 \mathrm{~cm}$ from the mouth of the tube. Then centrifuge in the same way. Place the centrifuge tube on the tube rack and drip the saturated sugar solution until it looks convex. Put the cover glass on it then wait 1-2 minutes. The coverslip was taken and placed on a slide which is examined under a microscope (Mumpuni et al., 2017).

\section{Data Analysis}

Samples of cow feces examined in Lobok Sub-District, Sumbawa District were declared positive samples if after examination of the feces found gastrointestinal protozoa. Positive samples were calculated using the Prevalence formula $=$ number of positive samples divided by the number of observed samples multiplied by $100 \%$. Data were analyzed using the Chi-square Test method to determine the effect of age on the prevalence of gastrointestinal protozoal infections.

\section{Results and Discussion}

The results of the examination obtained as many as 62 positive samples from a total of 100 samples so that the prevalence rate of gastrointestinal protozoa was $62 \%$. Sample collection from 7 villages in Lopok Sub-District, Sumbawa District showed that the samples were positive for gastrointestinal protozoa infection in each village (Table 1 ). 
Table 1. The Prevalence of gastrointestinal protozoa in Bali Cattle in Lopok Sub-District, Sumbawa District

\begin{tabular}{cccc}
\hline Village & Samples & $\begin{array}{c}\text { Positive } \\
\text { Samples }\end{array}$ & $\begin{array}{c}\text { Prevalence } \\
(\%)\end{array}$ \\
\hline Mama & 9 & 6 & 66.66 \\
Berora & 9 & 7 & 77.77 \\
Langam & 14 & 7 & 50 \\
Pungkit & 17 & 9 & 52.94 \\
Tatede & 4 & 1 & 25 \\
Lopok & 34 & 26 & 76.47 \\
Lopok & 13 & 6 & 46.15 \\
Beru & & & 62 \\
Total & 100 & 62 & \\
\hline
\end{tabular}

The results of laboratory examinations found 4 genera of gastrointestinal protozoa, namely Eimeria sp., Blastocystis sp., Entamoeba sp., and Balantidium sp. (Figs. 1 and 2).

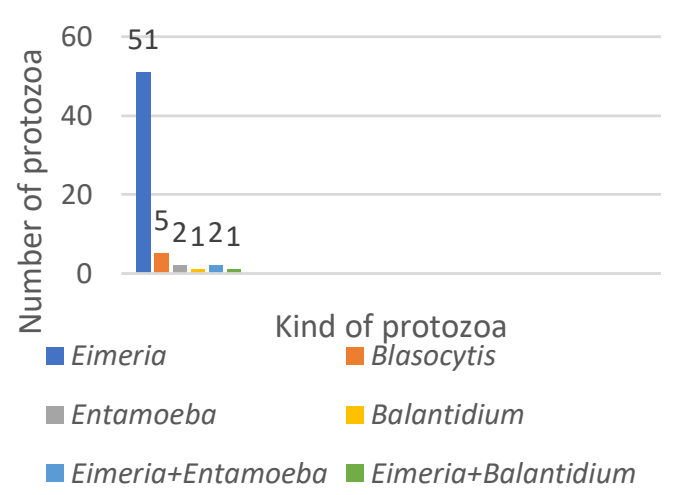

Figure 1. Types of gastrointestinal protozoa that infect Bali cattle in Lopok Sub-District, Sumbawa District.
Protozoa identification was done by observing the morphology of the shape and size of the protozoa. Protozoa were measured and observed with a microscope connected to an optilab. Types of Eimeria sp. was a single infection with 51 positive samples, Blastocystic sp. second single infection with 5 positive samples. Entamoeba sp. third single infection with 2 positive samples and Balantidium sp. with the lowest single infection of 1 positive sample. In mixed infections, there were 2 mixed infections, namely Eimeria sp. and Entamoeba sp. with 2 positive samples and Eimeria sp. and Balantidium sp. 1 positive sample (Table 2).

The results of statistical analysis using the chi-square method to determine the effect of age obtained an asymptotic significance value of $0.010 \%$, indicating that there was a significant difference $(\mathrm{P}<0.05)$ so that there was an effect of age on the prevalence of gastrointestinal protozoa. Age o- 6 months and 7 months -2 years has a significant difference to the age more than 2 years, while the age of $0-6$ months has no significant difference to the age of 7 months - 2 years. (Table 3).

The highest prevalence of protozoa in cattle aged o-6 months was found in Mama, Pungkit, and Lopok Beru villages (100\%) and the lowest in Berora and Langam villages (50\%). At age more than 2 years, the highest prevalence was found in Berora village $(66.7 \%)$ and the lowest was in Lopok Beru village (28.6\%).

Table 2. Types of gastrointestinal protozoa that infect Bali cattle in Lopok Sub-District, Sumbawa District

\begin{tabular}{cccccc}
\hline Village & Single Infection & Total & $\begin{array}{c}\text { Mixed } \\
\text { Infection }\end{array}$ & Total & Prevalence \% \\
\hline Mama Berora & Eimeria & 4 & - & -1 & 66.66 \\
Langam & Blastocystis & 2 & - & - & \\
Pungkit & Eimeria & 5 & Eimeria & -2 & 77.77 \\
& Balantidium & 1 & Balantidium & - & \\
TatedeLopok & Eimeria & 5 & - & - & 50 \\
& Entamoeba & 1 & - & - & \\
& Blastocystis & 1 & - & - & 52.94 \\
LopokBeru & Eimeria & 5 & Eimeria & - & 25 \\
& Eimeria & 1 & Entamoeba & - & 76.47 \\
& Blastocystis & 1 & - & - & 46.25 \\
\hline
\end{tabular}




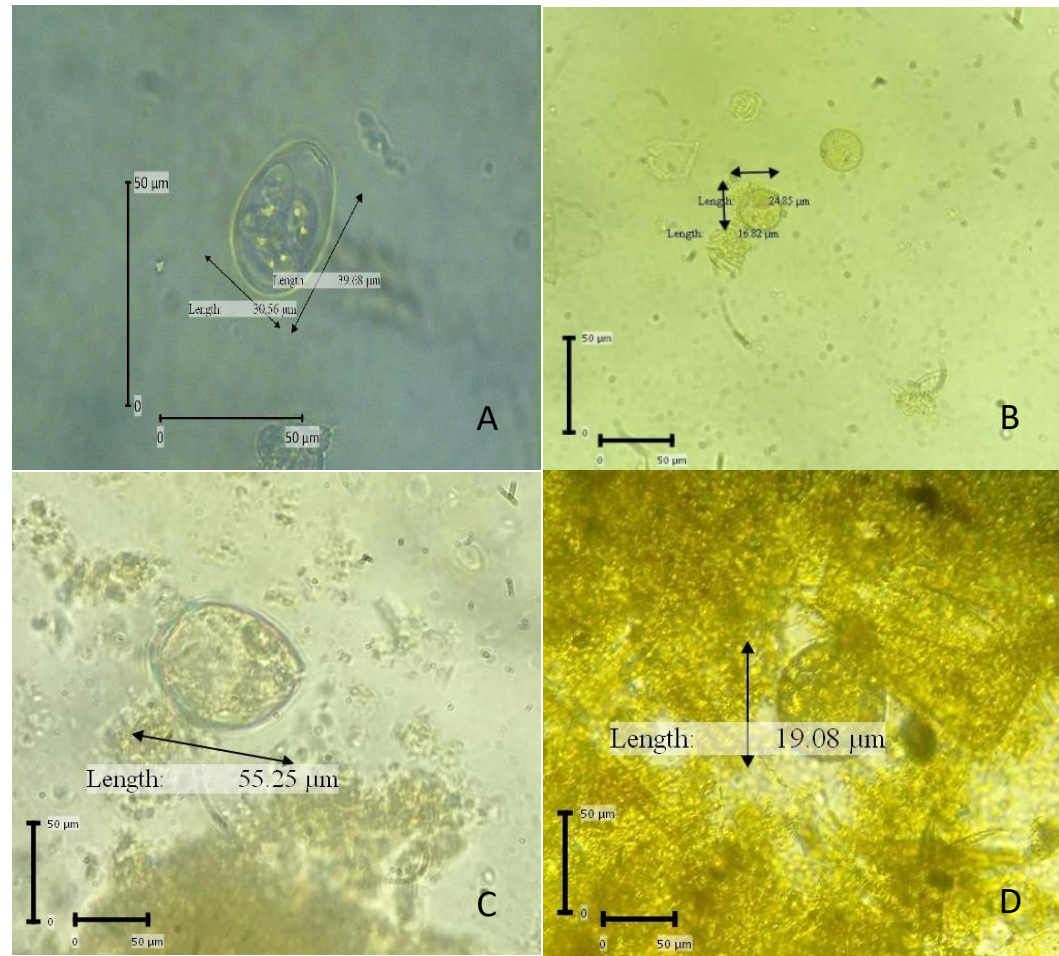

Figure 2. Gastrointestinal protozoa were found fecal sample of Bali cattle. A, Eimeria sp.; B, Blastocystis sp.; C, Balantidium sp.; D, Entamoeba sp. (40ox magnification)

Table 3. Effect of age on prevalence of gastrointestinal protozoa using chi-square analysis

\begin{tabular}{ccccc}
\hline Age & Protozoa & Samples & $\begin{array}{c}\text { Positive } \\
\text { Samples }\end{array}$ & Prevalence \% \\
\hline 0-6 months & Eimeria Eimeria + Entamoeba & 21 & 13 & $17(81)$ \\
& Blastocystis & & 2 & \\
7 months-2 years Eimeria Eimeria+ Balantidium & 37 & 2 & \\
& BlastocystisBalantidium & & 23 & $26(70.3)$ \\
& & 1 & \\
$>2$ years & Eimeria Blastocystis & 42 & 1 & \\
& Entamoeba & & 15 & $19(45.2)$ \\
& & 2 & \\
\hline
\end{tabular}

The prevalence results were found to have differences with various regions and regions. The prevalence of gastrointestinal protozoa is generally higher in developing countries (30$50 \%)$ than in developed countries $(1.5-10 \%)$. This is influenced by population density, poor environmental hygiene, lack of clean water supply and using water from the same source, and improper waste disposal system (Badparva et al., 2015). Other factors that can cause the high prevalence of protozoa are health standards, environmental hygiene, and consumption of contaminated water and feed (Alfellani et al., 2013).

Protozoal infections are strongly influenced by environmental conditions. The rainy season can increase soil moisture so that it becomes the cause of high protozoan infections. The rainy season with high humidity and low temperature is a favorable condition for protozoa to thrive. Parasite infection in livestock is also influenced by various factors, including geographical location, environmental conditions, quality of the cage, sanitation and hygiene, density of the cage, temperature, humidity, and vegetation (Marskole et al., 2016).

The results of interviews with owners of Bali cattle that are kept are rarely treated. Medications were given when there are livestock health services in the area and when the cows show symptoms of the disease. 
Eimeria sp. infection was found in all villages in Lopok Sub-District, Sumbawa District The highest prevalence of Eimeria was found in the village of Lopok $73.52 \%$ (25/34), Berora $66.66 \%(6 / 9)$ with 5 single infections and 1 mixed infection with Balantidium sp., Lopok Beru 46.15\% (6/13), Mama 44.44\% (4/9), Pungkit $41.17 \%$ ( $7 / 17)$ with 5 single infections and 2 mixed infections with Entamoeba sp., Langam 35.71\% (5/14) and Tatede village with the lowest prevalence of Eimeria sp. $25 \%$ (1/4) positive samples.

The highest prevalence of Eimeria sp. was found in cows aged o- 6 months with a prevalence of $71.90 \%(14 / 21)$ compared to those aged 7 months-2 years $64.86 \%(24 / 37)$ and the lowest prevalence was at $>2$ years of age. $35.71 \%$ $(15 / 42)$. The results of this study matching with the study by Heidari and Gharekhani (2014) that reported the age factor of cattle was strongly related to the high level of Eimeria infection. Calves are more susceptible to Eimeria infection because their immunity is still low or calves are infected from more mature cows when mixed in one cage. Eimeria infection in adult cows has previously enhanced the immune system in these cows perfectly so that adult cows are more resistant in the event of reinfection (Heidari et al. 2014).

Blastocystis sp. infection, in this study, was said to be still low, namely 5 positive samples with a percentage of $5 \%$ and found in 4 villages out of a total of 7 villages, namely Mama village 2 positive samples, Langam, Pungkit, and Lopok villages each 1 positive sample. Research shows Blastocystis has genetic diversity, as many as 13 subtypes (ST) have been identified from humans and animals (Noel et al., 2003).

Entamoeba sp., found in $4(4 \%)$ positive samples with 2 samples of single infection and 2 samples of mixed infection, found in Pungkit village as many as 3 positive samples and 1 positive sample in Langam village. Entamoeba sp. infection, each found 2 positive samples at the age of $0-6$ months and $>2$ years. Several

\section{Conclusion}

The prevalence of gastrointestinal protozoa in Bali cattle in Lopok Sub-District, Sumbawa District was $62 \%$. The types of protozoa found were Eimeria sp., Blastocystis sp., Entamoeba sp., and Balantidium sp. and there was an effect of age on the prevalence of gastrointestinal protozoa. previous studies reported on Entamoeba sp. infection, by Saputri et al. (2018) in the Mengwi Sub-District of Badung Bali showing a prevalence rate of $2.85 \%$, Rahmawati et al. (2018) in Bali cattle in wet and dry land in Badung District Bali 52.7\%.

Balantidium sp. infection, only found 2 samples at the age of 7 months - 2 years. The prevalence of Balantidium sp., in this study is categorized as low compared to several studies that have been reported in Indonesia including, Rahmawati et al. (2018) in Bali cattle in wet and dry land in Badung District 10.4\%, Saputri et al. (2018) in Bali cattle in Mengwi Sub-District Badung Bali 7.61\%.

Livestock rearing systems that still use extensive rearing systems can increase the risk of livestock being infected with protozoa. The prevalence of protozoa in cattle aged o- 6 months and 7 months -2 years is higher than those aged $>2$ years and cannot be separated from the behavior of the community in raising livestock which unites various ages of livestock and the lack of sanitation in grazing fields. Calves aged o- 6 months without being caged and grazing freely with other livestock in the grazing fields so that the risk of being infected with protozoa is higher both from grass and water sources that have been contaminated with the infective stage of the protozoa. According to Hastutiek et al. (2019), the habit of grazing in a wider area will increase the risk of livestock being infected with protozoa, cattle that are kept in cages or not will be susceptible to protozoan infections that have contaminated the grass they eat. The prevalence rate of gastrointestinal parasites is higher in young people compared to old age, the severity of gastrointestinal parasitic infections may be due to the animal's susceptibility to internal parasites and poor immunity. Prevalence rates and clinical disease may vary, based on different environmental factors in different areas (Gunathilaka et al., 2018).

\section{References}

Alfellani, M. A., Stenvold R., Vidal-Lapedra, A., Onouh, E.S.U Fagbenio-Beyioku and A., Clark, C.G. 2013. Variable Geographic Distribution of Blastocystis Subtypes and its Potential implication: 11-18.

Badpara, E., Fallahi, S. and Aarab-Mazar, Z. 2015. Blastocystis: Emerging protozoan with high prevalence in Iran. Nov. Biomed., 3(4):214-221. 
BPS Kabupaten Sumbawa. 2020. Kecamatan Lopok Dalam Angka 2019 https://Sumbawakab.bps.go.id/publicati on/download [23 Juli 2020].

Gunathilaka. N, Niroshana D, Amarasinghe D. 2018. Prevalence of Gastrointestinal Parasitic Infections and Assessment of Deworming Program among Cattle and Buffaloes in Gampaha District, Sri Lanka. DOI: 10.1155/2018/3048373.

Hastutiek, P, W. M. Yuniarti, Mufasirin, N. D. R. Lastuti, E. Suprihati, and L. T. Suwanti. 2019. Prevalence and Diversity of Gastrointestinal Protozoa in Madura Cattle At Bangkalan Regency, East Java, Indonesia. Veterinary Word, 12 (2) 198204.

Heidari, H. and J. Gharekhani. 2014. Detection of Eimeria species in Iranian native cattle. Int. J. Adv. Res.2(7):731-734.

Heidari, H., Z.S. Dehkordi, R. Moayedi, and J. Gharekhani. 2014. Occurrence and diversity of Eimeria species in cattle in Hamedan province, Iran. Vet. Med. 59(6):271-275.

Huang, C, L.Wang, C.Pan, C.Yang, and C.Lai.2014. Investigation of gastrointestinal parasites of dairy cattle around Taiwan. Journal of Microbiology, Immunology, and Infection.47(1):70-74

Kantzoura, V, Kouam MK, Theodoropoulou $\mathrm{H}$, Feidas $\mathrm{H}$, and G. Theodoropoulos. 2012. Prevalence and risk factors of gastrointestinal parasitic infections in small ruminants in the Greek temperate Mediterranean environment. Open Journal of Veterinary Medicine. (2): 2533.
Mumpuni, S., S. Subekti, S. Koesdarto dan Kusnoto. 2017. Penuntun Praktikum Ilmu Penyakit Helmint Veteriner. Fakultas kedokteran Hewan Universitas Airlangga. Surabaya. 7-10.

Noel, C., C. Peyronnet., D. Gerbod., V. Pedgcomb., P. Delgado-Viscogliosi., M. L. Sogin., M. Capron., E. Viscogliosi., and L. Zenner. 2003. Phylogenetic Analysis of Blastocystis Isolates from Different Hosts Based on The Comparison of Small-Subunit rRNA Gene Sequences. Mol. Biochem. Parasitol. 126:119-126.

Nugroho, A. 2014. Peran Tanah Sebagai Reservoir Penyakit. Vektora. 6 (1) :27- 32.

Rahmawati E, I. A. P. Apsari, I. M. Dwinata. 2018. Prevalensi Infeksi Protozoa Gastrointestinal pada Sapi Bali di Lahan Basah dan Kering di Kabupaten Badung. Indonesia Medicus Veterinus.7(4): 324334 .

Saputri, M, I. A. P. Apsari, I. B. M. Oka. 2018. Prevalensi dan Identifikasi Protozoa Gastrointestinal pada Sapi Bali di Kecamatan Mengwi, Kabupaten Badung, Bali. Indonesia Medicus Veterinus. 7(4): 384-392.

Susana, Y, Suprihati, E, L. T Suwanti. 2019. Identification and Prevalence of Gastrointestinal Parasites inBeef Cattle in Siak Sri Indrapura, Riau, Indonesia. Indonesian Journal of Tropical and Infectious Disease. 155-16o.

Widyani, R. 2013. Ilmu Lingkungan Ternak. Penerbit Swagati Press.

Zalizar, L. 2017. Helminthiasis Saluran Cerna Pada Sapi Perah. Jurnal Ilmu-Ilmu Pertenakan. 27(2):116-122. 